\title{
THE PARTICLE TRACK RECORD OF THE LUNAR SURFACE
}

\author{
G. M. COMSTOCK* \\ General Electric Research and Development Center, Schenectady, New York, U.S.A.
}

\begin{abstract}
Information about lunar surface history revealed by fossil particle tracks is summarized. Such tracks are the result of damage !eft in dielectric materials by highly ionizing charged particles including heavy solar and galactic cosmic ray nuclei, heavy nuclei recoiling from cosmic ray induced spallation reactions and induced- and spontaneous-fission fragments. From the distribution of cosmic ray and spallation tracks in the lunar rock, surface residence times of 1 to 30 million yr and rock erosion rates of 1 to $10 \AA / \mathrm{yr}$ have been determined. Particle tracks also record surface orientation and depth history of the rocks and contain information about ancient solar activity. The distribution of particle tracks in lunar soil is found to be consistent with a model which includes repeated excavation, layering and burial. With this model one core $12025+28$ soil layer can be identified as unmixed and weakly irradiated; the others contain soil which has been better and better mixed and more and more irradiated.
\end{abstract}

\section{Introduction}

The study of fossil particle tracks in lunar material has yielded much information concerning the history of lunar rocks and soil as well as ancient levels of energetic particle fluxes (Barber et al., 1971a, b; Bhandari et al., 1971; Borg et al., 1971a, b; Comstock et al., 1971; Crozaz et al., 1970, 1971; Fleischer et al., 1970b, c, 1971a, b; Lal et al., 1970; Price et al., 1970b, 1971; Arrhenius et al., 1971).

In this paper we summarize some of the results of particle track studies in lunar materials and develop further the conclusions that can be drawn from track densities in soil grains. We first summarize briefly the possible sources of lunar particle tracks. The production rates of cosmic ray and spallation tracks are then discussed and interpretation in terms of rock exposure ages and erosion rates are summarized. The last part of the paper is devoted to a discussion of the layering, mixing and irradiation history of the soil, based on the track distributions observed in the Apollo 12 double core.

\section{Sources of Lunar Particle Tracks}

Fossil particle tracks mark the damaged region left in dielectric materials by the passage of highly ionizing charged particles. If the particles are sufficiently ionizing they cause permanent disruptions of the lattice structure (Fleischer et al., 1967). Laboratory evidence (Fleischer et al., 1970d) indicates that in lunar crystals the annealing or erasure of tracks due to temperatures normally experienced on the Moon can be considered negligible. When introduced to the proper chemical etchant the damaged tracks can etch faster than the general surface resulting in a cone-shaped cavity. For a given etching time the shape of the cone depends on the charge and energy of the incident particle; in particular the cone length depends strongly on the rate of primary ionization (Price et al., 1967).

In a given material there is an ionization rate, or registration threshold below which

* Now at Centre de Spectrométrie de Masse du C.N.R.S., 91 - Orsay, France. 
there will not be sufficient damage to result in an etchable track. In lunar materials this threshold allows the registration of nuclei heavier than $Z \sim 20$ (calcium) (Plieninger and Krätschmer, 1971). These nuclei are therefore observable over that portion of their range where the rate of primary ionization exceeds the registration threshold.

In Table I we have listed the possible sources of particles capable of leaving etchable tracks in lunar material. This list also applies to meteorites for which many of the

\section{TABLE I}

Possible sources of tracks on the Moon

(1) Cosmic ray tracks - Solar and galactic nuclei with charge $Z>20-23$.

(2) Spallation tracks - Heavy nuclei recoiling form spallation reactions induced by primary and secondary cosmic ray protons, neutrons and alpha particles.

(3) Fission tracks - Fragments form spontaneous fission of $\mathrm{U}^{238}, \mathrm{Pu}^{244}$ and possibly super-heavy elements.

(4) Induced fission tracks - Fission induced by cosmic ray protons on $\mathrm{Pb}$, Th or $\mathrm{U}$ or by secondary neutrons.

Also

(5) Meson jets induced by very high energy cosmic rays (rare).

(6) Dirac monopoles (hypothetical).

techniques used to study particle tracks were developed (Fleischer et al., 1967; Price et al., 1968a; Pellas et al., 1969; Walker, 1970). Monopoles, if they exist (Fleischer et al., 1970a), would have to leave tracks $\gtrsim \frac{1}{2} \mathrm{~cm}$ long in order not to be confused with the heaviest cosmic ray tracks (Fleischer et al., 1967; Barber et al., 1971a).

Spontaneous and cosmic-ray-induced fission tracks are important constituents of particle tracks on the Moon, although the only reported cosmic-ray-induced fission events are those found in a sample of lead-bearing filter glass that was part of the Surveyor 3 spacecraft (Fleischer et al., 1971b). The study of spontaneous fission tracks in terrestrial materials has led to the very fruitful field of fission-track dating (reviewed by Fleischer and Hart, 1970d).

On the Moon, however, fission track densities are generally much less than cosmic ray and spallation track densities except in certain uranium-rich minerals (Burnett et al., 1971) and perhaps at great depths (which have been shielded from cosmic rays). Lunar fission tracks can be studied by mapping uranium-rich inclusions (Crozaz et al., 1970; Fleischer et al., 1970c) or by investigating excess track densities along crystal cleavages which often represent grain boundaries where heavy elements concentrate (Bhandari et al., 1971). Bhandari et al. report that these excess tracks tend to be longer (13-25 $\mu \mathrm{m})$ than the abundant iron tracks $(10-13 \mu \mathrm{m})$ and interpret their results as evidence for the primordial existence of $\mathrm{Pu}^{244}$ and possibly of super-heavy elements.

By far the most abundant particle tracks on the Moon are the cosmic ray and spallation recoil tracks (as used here the term cosmic ray includes solar as well as extra-solar 


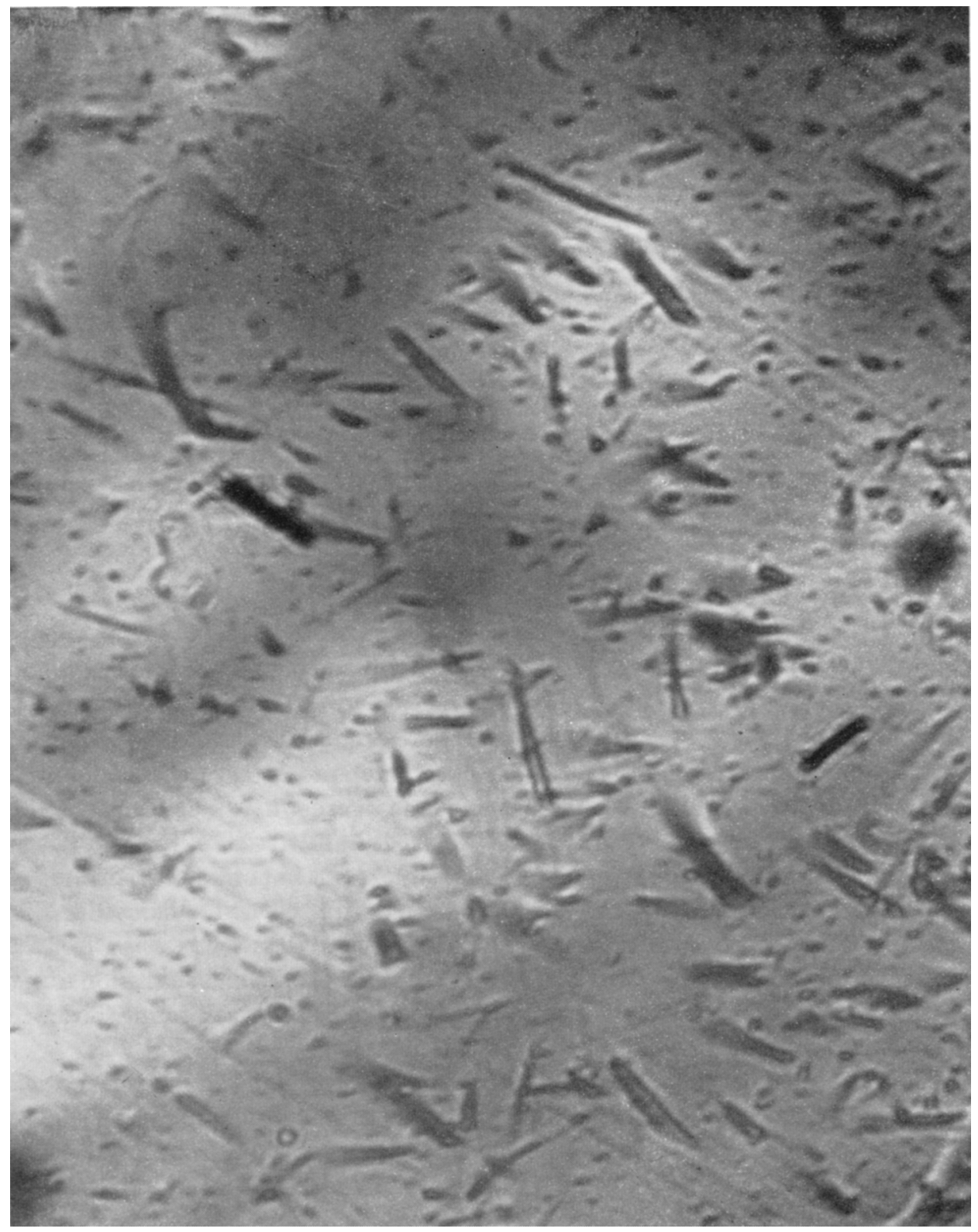

Fig. 1. Optical photograph of cosmic ray tracks (comet-shaped) and spallation tracks (dots) in a lunar crystal. 
or galactic particles.) An optical photograph (transmitted light) of a sample of these tracks is shown in Figure 1. The long comet-shaped objects - cosmic ray tracks, $\lesssim 11 \mu \mathrm{m}$ - were produced primarily by cosmic ray iron nuclei, the most abundant species which will register tracks. Their density here is only a few million per $\mathrm{cm}^{2}$ which is relatively low for lunar material. The dots - spallation tracks - are very short tracks left by heavy nuclei recoiling from cosmic-ray-induced spallation reactions.

In addition to the dominant iron tracks there occasionally occur longer tracks resulting from heavier cosmic rays. Price et al. (1971) have reported such tracks, including two tracks most likely from lead- or uranium-like nuclei. Such long tracks may allow us to study the ancient relative abundances of extremely heavy cosmic ray nuclei, provided we can determine the depth history of the rock (the heavier nuclei are more strongly attenuated with depth).

\section{Cosmic Ray and Spallation Tracks}

In order to understand what the cosmic ray and spallation track record can tell us about lunar surface history, we first must know the depth dependence of the production rate of these tracks. For the cosmic ray tracks we need the average energy spectrum of the heavy cosmic ray nuclei, predominately the iron group, shown in Figure 2. The spectrum is composed of two parts: a lower-energy solar contribution resulting from solar flare activity and a galactic contribution at higher energies.

The relative nuclear abundances and shape of the galactic spectrum have been measured in satellite and balloon experiments (Comstock et al., 1969; Freier and Waddington, 1968; Price et al., 1970a; Garcia-Munoz and Simpson, 1970) during times of minimum solar activity. We have corrected this shape for the average effect of solar modulation over the 11-yr solar cycle using a model by Wang (1970). The contribution of each species to the production of etchable tracks is proportional, among other things, to the etchable track length $\Delta R(Z)$ and the relative abundance $A(Z)$. The abundance $A(Z) \approx 0$ for species with $Z>26$ and $\Delta R(Z)=0$ for $Z<20-23$ for lunar material (Bhandari et al., 1971b; Plieninger and Krätschmer, 1971). Measured $A(Z)$ and plausible values of $\Delta R(Z)$ are listed in Table II.

The other factors which contribute to the track production rate (see Equation 2) have much weaker charge dependences over the dominant charge interval. Hence we may define an equivalent iron-like flux given by

$$
\left(\begin{array}{l}
\mathrm{d} N \\
\mathrm{~d} T
\end{array}\right)_{E}=\left(\frac{\mathrm{d} N}{\mathrm{~d} T}\right)_{\mathrm{Fe}} \sum_{\text {all } Z}\left(\frac{\Delta R(Z)}{\Delta R(\mathrm{Fe})}\right)\left(\frac{A(Z)}{A(\mathrm{Fe})}\right)
$$

where $(\mathrm{d} N / \mathrm{d} T)$ is the differential particle flux. The values listed in Table II yield

$$
\left(\begin{array}{l}
\mathrm{d} N \\
\mathrm{~d} T
\end{array}\right)_{E}=1.63\left(\begin{array}{l}
\mathrm{d} N \\
\mathrm{~d} T
\end{array}\right)_{\mathrm{Fe}}=0.52\left(\begin{array}{l}
\mathrm{d} N \\
\mathrm{~d} T
\end{array}\right)_{\mathrm{VH}}
$$

Equation ( $\mathrm{lb}$ ) gives the equivalent flux, corrected for average solar modulation, 


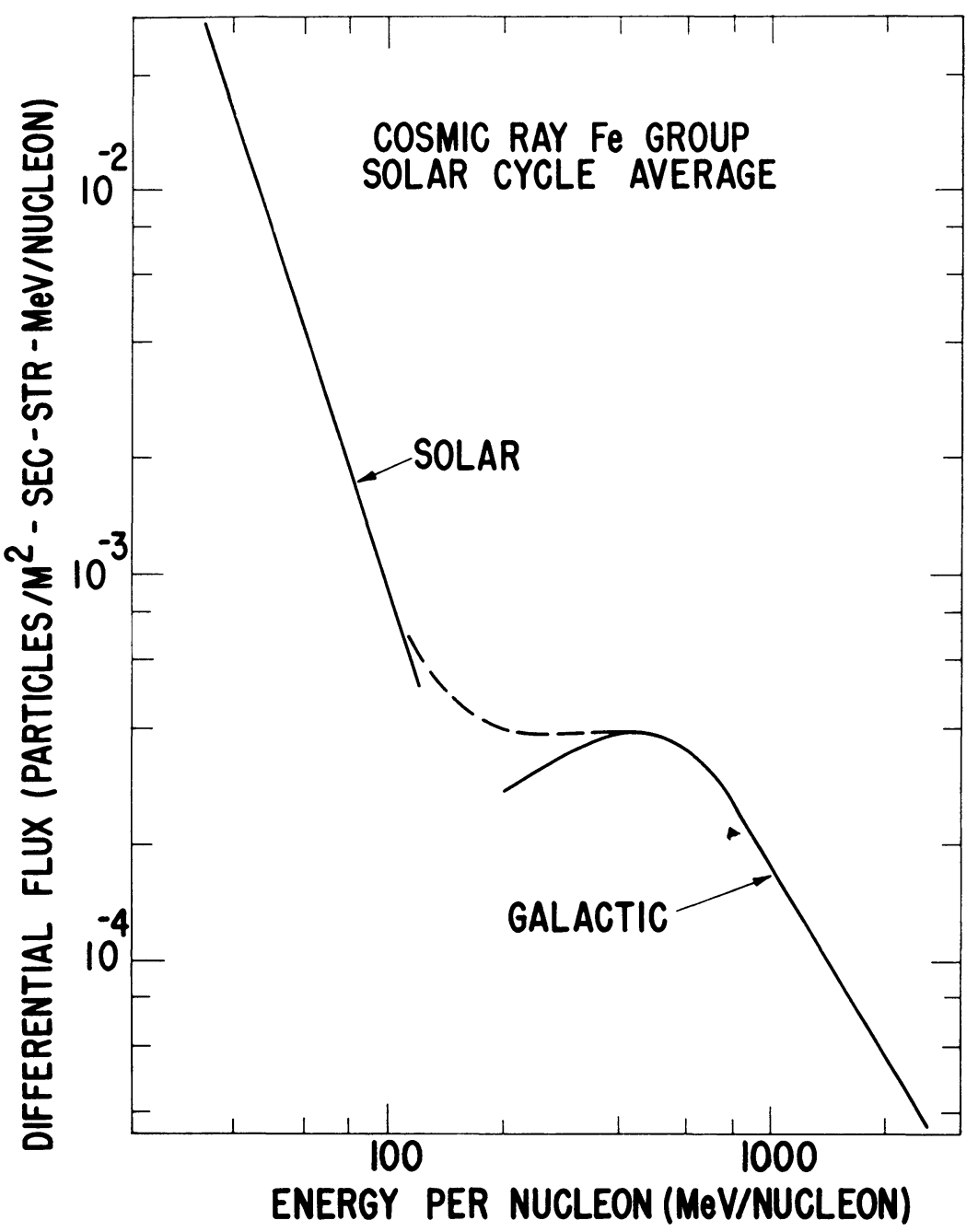

Fig. 2. Average differential energy spectrum of equivalent iron-like flux capable of leaving etchable tracks in lunar material (see text and Equation (1b)).

which is plotted for the galactic contribution in Figure 2. This flux is about a factor of two less than that given by Fleischer et al. (1967) and Crozaz et al. (1970), which is the total flux of the larger VH charge group $(Z \geqslant 20)$ treated as entirely iron, so that

$$
\left(\frac{\mathrm{d} N}{\mathrm{~d} T}\right)_{E}=\left(\frac{\mathrm{d} N}{\mathrm{~d} T}\right)_{\mathrm{vH}}
$$

Note that the lower flux of Equation (1b) will imply correspondingly greater galactic cosmic ray exposure times than values based on the higher flux of Equation (1c). Plieninger and Krätschmer (1971) report that the registration threshold may in fact 
TABLE II

\begin{tabular}{lrcc}
\hline Species & \multicolumn{1}{c}{$Z$} & $A(Z)^{\mathrm{a}}$ & $\Delta R(Z)^{\mathrm{b}}$ \\
\hline & & & \\
- & $<23$ & - & 0 \\
vanadium & 23 & 0.20 & $2.5 \mu \mathrm{m}$ \\
chromium & 24 & 0.55 & 5.5 \\
manganese & 25 & 0.44 & 8.5 \\
iron & 26 & 1.00 & 11.5 \\
- & $>26$ & $\approx 0$ & - \\
\hline
\end{tabular}

a Average of Price et al. (1968b, 1970a) and GarciaMunoz and Simpson (1970).

b Bhandari et al. (1971b) (but see Plieninger and Kratschmer, 1971, and Rajan and Price, 1971, who report larger values of $\Delta R(Z)$ ).

be as low as $Z=20(\mathrm{Ca})$ in which case the equivalent flux $(\mathrm{d} N / \mathrm{d} T)_{E}$ will be greater than that given by Equation (1b). However, the contribution from the species $\mathrm{Ca}-\mathrm{V}$ will be small because of their lower values of $A(Z)$ and $\Delta R(Z)$ (see note added in proof).

For the solar contribution we rely on the energy spectrum derived from cosmic ray tracks observed in a piece of Surveyor 3 filter glass (Garber et al., 1971a; Crozaz et al., 1971; Fleischer et al., 1971b). The registration thershold for this glass is somewhat lower than for lunar minerals, however, the relative abundances of solar flare species P-Mn is so low that the charge interval effectively recorded by the Surveyor 3 glass is essentially the same as that recorded by lunar material (Fleischer et al., 1971b). The major uncertainty in applying the Surveyor 3 flux to lunar material is that the Surveyor 3 spacecraft was on the Moon for only a fraction of the present solar cycle, about $2.6 \mathrm{yr}$, during the period of maximum solar activity. It is not certain how the Surveyor 3 flux relates to the average solar contribution over many solar cycles. If the present cycle is typical then the average solar flux should be about half of the observed Surveyor 3 flux, as plotted in Figure 2. Crozaz et al. (1971) use a higher flux.

From this composite energy spectrum we calculate the production rate of cosmic ray tracks in lunar material, given by

$$
\dot{\varrho}(\mathbf{r})=\alpha \int_{\Omega}\left(\frac{\mathrm{d} N}{\mathrm{~d} T}\right)_{E}\left(\frac{\mathrm{d} T}{\mathrm{~d} R}\right)_{\mathrm{Fe}} \Delta R(\mathrm{Fe}) e^{-\chi(\theta, \Phi) / \lambda} p(\theta, \Phi) \mathrm{d} \Omega
$$

where $\alpha$ is the etching efficiency, $(\mathrm{d} N / \mathrm{d} T)_{E}$ is the equivalent iron-like flux defined earlier, evaluated at $T$ which is the incident kinetic energy per nucleon corresponding to range $\chi(\theta, \Phi)$ in lunar rock or soil, $(\mathrm{d} T / \mathrm{d} R)_{\mathrm{Fe}}$ is the rate of energy loss of iron in lunar minerals evaluated at $T, \lambda$ is the mean particle loss path length due to nuclear interactions, $p(\theta, \Phi)$ is a projection function which takes into account the orientation of the etched surface with respect to rock or soil surface (Fleischer et al., 1967), and $\chi(\theta, \Phi)$ is the particle path length from the sample point to the surface in the direction 
of the solid angle increment $\mathrm{d} \Omega$. Since the original orientation of the etched surface is often unknown, we compute the average production rate for a set of randomly oriented crystals for which case $p(\theta, \Phi)=\frac{1}{2}$.

The cosmic ray track production in lunar soil derived in this way is shown in Figure 3. It is clear from this curve that we expect a steep gradient in track density within a millimeter of the exposed surface. This steep production rate extends down to within $\sim 1 \mu \mathrm{m}$ of the surface as discussed at this conference by Borg et al. (1971b).

The second curve shown in Figure 3 is the spallation track production rate determined from the high energy cosmic ray proton flux and from laboratory production experiments (Kohman et al., 1967), including calibration of the response of individual lunar grains (Fleischer et al., 1971a - experimentally, the magnitude of the produc-

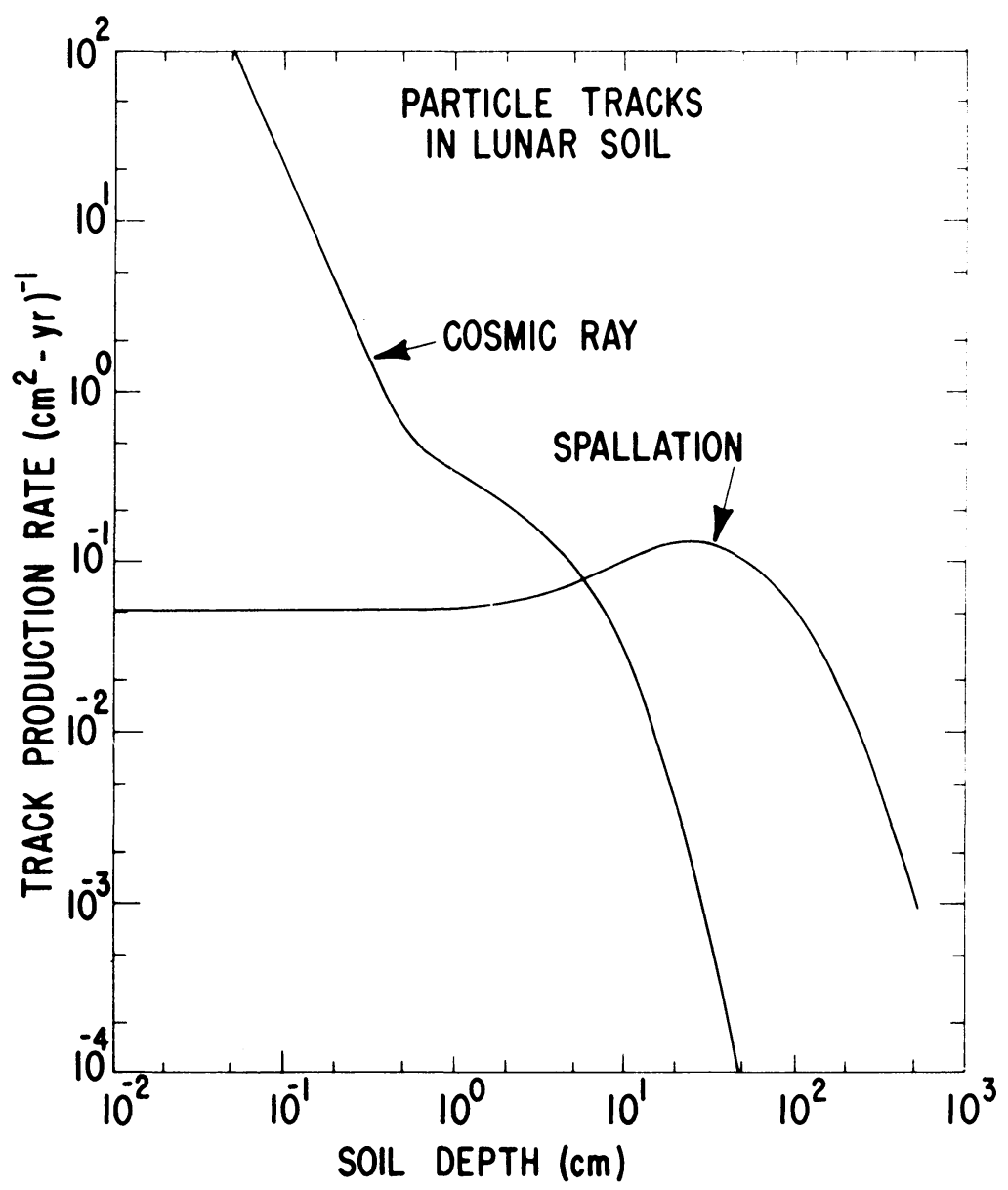

Fig. 3. Calculated rate of production of cosmic ray tracks (from Equation (2) with $\Delta R(\mathrm{Fe})=11.5$ $\mu \mathrm{m})$ and empirical production rate of spallation tracks, shown for semi-infinite lunar soil (density $1.6 \mathrm{gm} \mathrm{cm}^{-3}$ ). These curves apply also to semi-infinite rock if the depth scale is decreased by a factor of about 2. 
tion rate in individual grains was found to vary by $\pm 70 \%$ from the average value indicated in Figure 3). Because of the production of various secondary particles capable of inducing spallation reactions, the production of spallation recoil nuclei capable of leaving etchable tracks rises to a maximum at about $25 \mathrm{~cm}$ of soil.

We emphasize that these two production curves have very different shapes so that each yields different information about the history of a sample. Spallation tracks record the time spent in about the upper two meters of soil. Most of the cosmic ray tracks, on the other hand, were formed while the rocks or soil grains were situated on or within a few centimeters of the surface.

\section{Lunar Rocks and Erosion Rates}

We define for the rocks two spallation track residence times: the 'surface age' determined by assuming that irradiation occurred entirely on the surface, and a 'minimum age' which assumes that the irradiation occurred at the maximum rate. Typical track ages are given in Table III along with radiometric spallation ages determined by various workers.

TABLE III

Fossil track ages $\left(10^{6} \mathrm{yr}\right)$ of lunar rocks

\begin{tabular}{|c|c|c|c|c|c|}
\hline \multirow{3}{*}{$\begin{array}{l}\text { Sample } \\
\text { number }\end{array}$} & \multirow{2}{*}{\multicolumn{2}{|c|}{$\begin{array}{l}\text { Cosmic ray surface residence } \\
\text { times top/bottom }\end{array}$}} & \multicolumn{2}{|c|}{ Spallation recoil tracks ${ }^{c}$} & \multirow{3}{*}{$\begin{array}{l}\text { Radiometric } \\
\text { spallation ages }^{d}\end{array}$} \\
\hline & & & \multirow{2}{*}{$\begin{array}{l}\text { Surface } \\
\text { age }\end{array}$} & \multirow{2}{*}{$\begin{array}{l}\text { Minimum } \\
\text { age }\end{array}$} & \\
\hline & $(\text { High age })^{a}$ & $(\text { Low age })^{b}$ & & & \\
\hline 10017 & 11.2 total & 5.7 total & 420 & 170 & $200-640$ \\
\hline 10044 & 8.4 total & 4.3 total & 270 & 110 & $56-100$ \\
\hline 10049 & 57 total & 29 total & 21 & 8.5 & $22.5-25$ \\
\hline 12002 & $47 / 0$ & $24 / 0$ & 55 & 20 & $50-145$ \\
\hline 12017 & $1.4 / 2.0$ & $0.7 / 1.0$ & 105 & 40 & - \\
\hline 12021 & $25 / 25$ & $13 / 13$ & 740 & 300 & 300 \\
\hline 12065 & $27 / 0$ & $14 / 0$ & 170 & 70 & $160-200$ \\
\hline
\end{tabular}

a From Equation (1b) and $\Delta R(\mathrm{Fe})=11.5 \mu \mathrm{m}$.

b Fleischer et al. (1970c, 1971a) using Equation (1c). Note that the Low age is also consistent with Equation (1a) and $\Delta R(\mathrm{Fe}) \approx 20 \mu \mathrm{m}$ (Rajan and Price), so that the High and Low ages represent the limits of uncertainty in $\Delta R(\mathrm{Fe})$. (See note added in proof.)

c Fleischer et al. (1971a).

d Spread of values from various authors, see Fleischer et al. (1971a) for references.

A typical rock studied has a radius of a few centimeters, so that the cosmic ray track density at its center is due primarily to galactic cosmic rays. If the rock erosion rate is not too great these central tracks may be used to find the 'cosmic ray surface residence time' $T_{s}$ by assuming

$$
T_{s}=\varrho(R) / \dot{Q}(R)
$$

where $Q(R)$ is the observed track density at the center of the rock and $\underline{\dot{Q}}(R)$ is calculated 
taking into account the shape and orientation of the rock. In Table III we have listed some values if $T_{s}$ based on both Equation (1b) (High age) and on Equation (1c) (Low age) (see note added in proof).

The spallation and radiometric ages in Table III show the same trend from rock to rock. Most of these ages are greater than the cosmic ray surface residence times, indicating that the rocks have resided for some time below the surface but within the top $2 \mathrm{~m}$. For rocks 10049 and 12002 the spallation surface ages and radiometric ages are comparable to the cosmic ray surface residence times indicating a simpler history. Rocks 12002 and 12065 have been irradiated on one side only.

Close to the surface of the rock, for a side which was facing up at some time, one finds a cosmic ray track gradient due to the solar flare particles (Figure 4). A similar gradient on the opposite side indicates that the rock has had more than one orientation on the lunar surface. The observed gradient is generally less than the gradient predicted

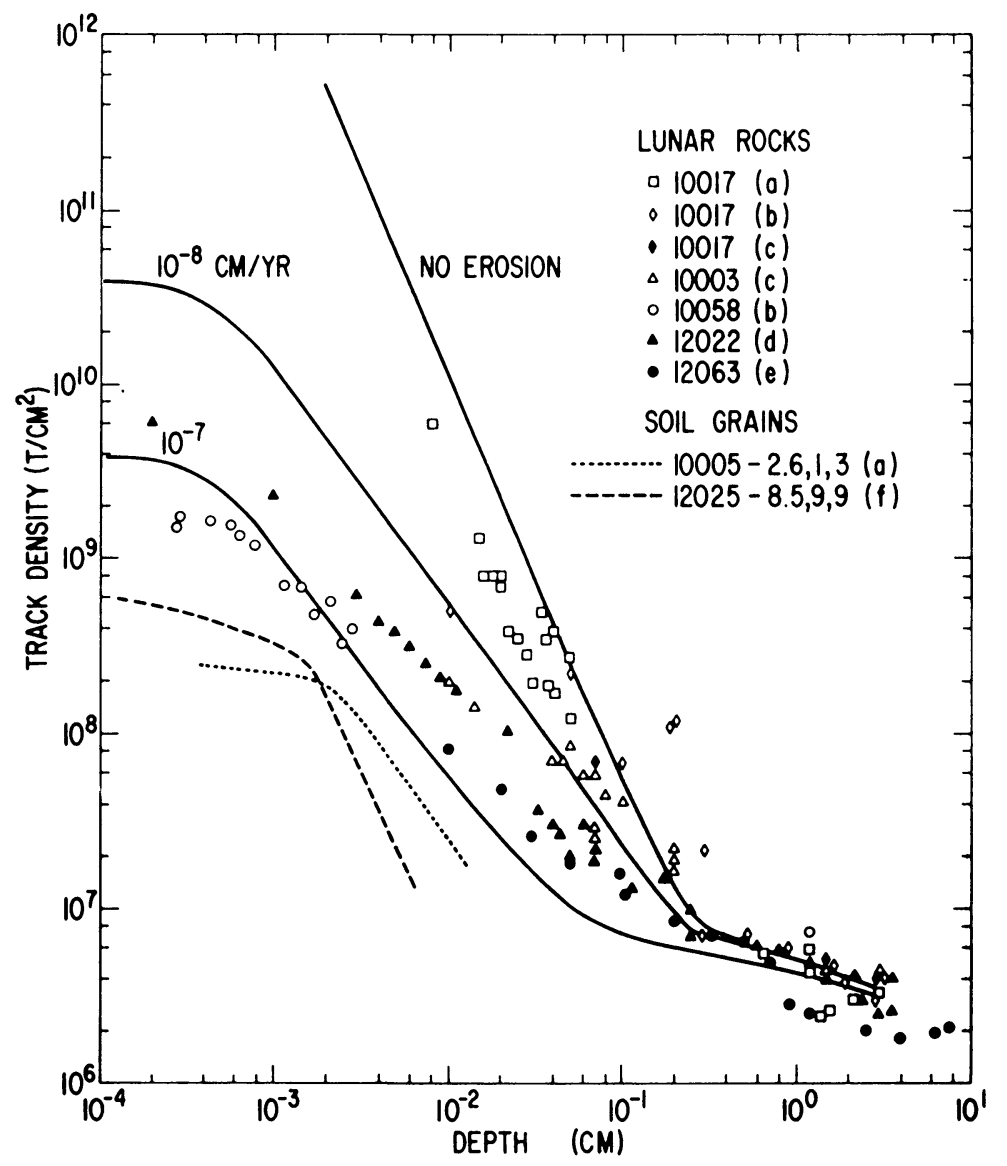

Fig. 4. Cosmic ray track gradients observed in several lunar rocks and two soil grains. The solid curves are calculated for a typical rock undergoing no erosion, and for two finite erosion rates. (a) Fleischer et al. (1970c), (b) Crozaz et al. (1970), (c) Price and O'Sullivan (1970b), (d) Barber et al. (1971a), (e) Crozaz et al. (1971), (f) Fleischer et al. (1971a) and Figure 5. 
by Equation (2) which has an exponent of about -2.4 . This is generally regarded as an effect of rock erosion (Crozaz et al., 1970, 1971; Fleischer et al., 1971b; Barber et al., 1970b, 1971a, b.)

In Figure 4 the solid curves refer to a vertical cross section through a spherical rock of final radius $3 \mathrm{~cm}$ which has resided in one orientation on the surface for $T_{s}=15 \mathrm{~m} . \mathrm{y}$. The no-erosion curve is derived from Equation (1b), (2) and

$$
\varrho(d)=\dot{\varrho}(d) T_{s} .
$$

The curves for finite erosion rates $e=10^{-8} \mathrm{~cm} \mathrm{yr}^{-1}$ and $10^{-7} \mathrm{~cm} \mathrm{yr}^{-1}$ are derived from Equation (1b), (2) with a time-dependent radius $r=R+e\left(T_{s}-t\right)$ and

$$
\varrho(d, e)=\int_{0}^{T_{s}} \dot{\varrho}(d, e t) \mathrm{d} t=\frac{1}{e} \int_{R}^{R+e T_{s}} \dot{\varrho}(d, r) \mathrm{d} r,
$$

where $d$ is the final depth below the rock surface, $e$ is the erosion rate and $R$ is the final radius.

These curves are not meant to fit any particular rock. For $\varrho$ near the center of a given rock we must take into account its shape and size, the time it has spent in each orientation on the lunar surface and the possible contribution from irradiation before direct surface exposure. For example, rock 12063 has spent less time on the surface than the others. Below about $1 \mathrm{~mm}$, however, the track density is essentially independent of the size and shape of the rock. Still closer to the surface the track density in an eroding rock becomes independent of the surface residence time as well, as the production rate comes into equilibrium with the eroding surface. More precisely, as the surface residence time $T_{s}$ increases the track density at each depth approaches a maximum or equilibrium value given by

$$
\varrho_{E}(d, e)=\frac{1}{e} \int_{R}^{\infty} \dot{\varrho}(d, r) \mathrm{d} r .
$$

For surface residence times on the order of 10 m.y. the track densities derived from Equation (5) coincide with the equilibrium values at depths less than a few hundred microns for erosion rates $e \leqslant 10^{-7} \mathrm{~cm} \mathrm{yr}^{-1}$. Greater depths (to $d \sim \mathrm{e} T_{s}$ ) would also be in equilibrium if it were not for the effects of the galactic contribution and the finite size of the rock. Below a few hundred microns, therefore, the magnitude of the track density depends only on the erosion rate and the average flux of solar flare particles (Equation (6)). The slope of the track gradient in this near-surface region depends on the exponent of the solar flare energy spectrum but may be modified by irregular erosion or chipping, unevenness of the surface near the sample point and possible loss of surface material during transport from the Moon. For example if rock 10058 has lost $\sim 10 \mu$ (one layer of rather small grains) during transport then it should be plotted coincident with rock 12022 in Figure 4.

The data shown in Figure 4 (see references in figure caption) indicate erosion rates 
varying from $e<10^{-8} \mathrm{~cm} \mathrm{yr}^{-1}$ for 10017 to $3 \times 10^{-8} \mathrm{~cm} \mathrm{yr}^{-1}$ for 12022 and $\sim 5 \times$ $\times 10^{-8} \mathrm{~cm} \mathrm{yr}^{-1}$ for 12063. Crozaz et al. (1971) argue that the average solar particle flux may be a factor of 2 greater than we have used in deriving the curves in Figure 4 and hence obtain proportionally higher erosion rates. The low value implied for 10017 may indicate that there have been wide fluctuations in the micrometeoroid flux at the Moon's surface. 10017 may have spent most of its surface exposure timeduring a period of meager micrometeoroid activity, then was buried and brought to the surface again less than $0.3 \mathrm{~m} . \mathrm{y}$. ago (corresponding to $<100 \mu$ of erosion at the rate of $3 \times 10^{-8}$



Unique opportunities to study solar flare activity in the past without the uncertainties of rock erosion are provided by rocks which have been recently covered with a glass coating; the best example of this is rock 12017 (Fleischer et al., 1971a). Although cosmic ray tracks in the center of the rock indicate that 12017 has been on the surface for at least 1.7 m.y., cosmic ray tracks found in grains imbedded within the glaze itself indicate that the glaze has been exposed on the rock for only $9000 \mathrm{yr}$. These tracks show the decrease with depth arising from solar flare particles. The glass coating is much less retentive of tracks than the mineral crystals; tracks in the glaze should fade away after about $500 \mathrm{yr}$ on the lunar surface due to thermal annealing (Fleischer et al., 1971a). The track density in the glaze also decreases with depth but has a lower magnitude than the track density in imbedded crystals, consistent with the $\sim 500 \mathrm{yr}$ retention time and the present flux of solar flare particles.

\section{Lunar Soil}

The record of particle tracks in the individual soil grains indicates a history even more complex than that of the rocks. (Hereinafter, the phrase 'track density' will refer to cosmic ray tracks, not spallation tracks, unless otherwise noted.) For the purposes of discussion we may divide the soil grain samples into three groups according to track density: (1) $\varrho \gtrsim 5 \times 10^{8} \mathrm{~cm}^{-2}$, (2) $\varrho$ with a strong gradient, and (3) $\varrho \lesssim 5 \times 10^{8} \mathrm{~cm}^{-2}$.

(1) Grains with high track densities include very many micron-sized grains and micron-deep coatings on larger grains(Borg et al., 1971 a, b) containing $10^{10}-10^{12} \mathrm{~cm}^{-2}$. Very high densities have also been reported throughout some larger grains $(\sim 100 \mu$ radius) (Crozaz et al., 1971; Barber et al., 1971a, b). These track densities must be the result of direct exposure to space for $T_{s} \sim 10^{4}-10^{5} \mathrm{yr}$ for the micron-sized grains and considerably longer for the larger grains.

(2) The second class of samples includes grains of $\sim 100$ micron-radius which contain a steep track density gradient extending inward from one or two edges. These have track densities typically approaching $\varrho \sim 10^{9} \mathrm{~cm}^{-2}$ in the outer $10 \mu$ dropping to $\varrho \sim 2 \times 10^{7} \mathrm{~cm}^{-2}$ in the center or low-density edge. A contour map of one such gradient is shown in Figure 5. Contours such as this may be strongly affected by the shape of the grain but in general they are what one expects if the grain had been exposed on the lunar surface in a particular orientation and covered by no more than several microns of dust. 
SAMPLE $12025,4,54-8.5,9,9$

CONTOURS IN $10^{8}$ TRACKS $/ \mathrm{CM}^{2}$

- TRANSMISSION MICROGRAPH COUNT

---- OPTICAL COUNT $\times 3$

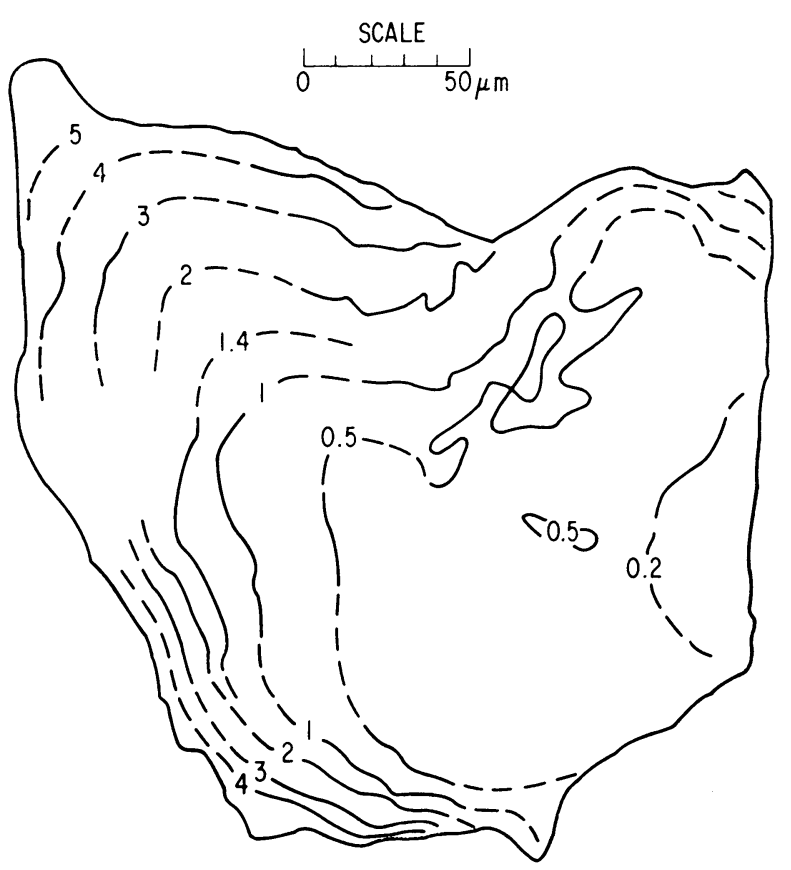

Fig. 5. Contour map of cosmic ray track density in a pyroxene soil grain with strong track gradient. The grain was found $8.5 \mathrm{~cm}$ below the lunar surface.

Track density profiles measured at $7500 \times$ along the steepest track gradients of two such grains are shown in Figure 4. There are two possible conditions under which tracks may have been accumulated to produce such gradients: (1) the grains were tossed randomly to the very surface as part of an ejecta blanket and later buried, or (b) the tracks accumulated while the grains were still part of an eroding rock, eventually being exposed, chipped out and buried in the soil.

Consider first case (a). The dominant erosion processes are discrete events, well separated in time, which will tend to destroy or bury a soil grain. Hence while the grain is on the surface (case a) the acquired track gradient should follow a no-erosion curve given by Equation (4) for some surface residence time $T_{s}$. In this case we interpret the sharp breaks in these curves at $\approx 20 \mu$ as being due to an (uncorrected-for) shielding of several microns of dust, which is reasonable considering the cohesiveness of the soil. For the soil grains plotted in Figure 4 we infer $T_{s} \sim 10^{4}$ yr., which is consistent with the rate of disturbance of a surface grain by micrometeoroid bombardment (Shoemaker et al., 1970).

If case (a) is the predominant condition for soil-grain gradient production, then we 
should expect a wide range of track densities from grain to grain corresponding to an exponential distribution in surface residence times. This in turn would yield information on the rate of disturbance of the surface.

In case (b) the track gradient in the grain represents the gradient which existed in the upper $\sim 100 \mu$ of the parent rock at the time when the grain was chipped out. (The grain could not have come from the interior of the rock since in that case the observed gradient would be too steep.) Hence the track gradients for the soil grains in Figure 4 should be fitted by equilibrium curves satisfying Equation (6) for whatever erosion rates were experienced by the parent rocks. The implied erosion rate is $\approx 3 \times 10^{-7}$ $\mathrm{cm} \mathrm{yr}^{-1}$ for both grains shown, or about an order of magnitude greater than the average rate observed in the rocks presently on the surface. This higher rate presumably would be related to the greater rate of meteoroid bombardment early in the Moon's history which would imply an early epoch for the formation of these soil grains from their parent rocks. If case (b) is the predominant condition for soil-grain gradient production, then we should expect a relatively narrow range of track densities from grain to grain ( $\sim$ factor of 10 ) corresponding to the distribution of erosion rates experienced during the period of soil formation. Rock 10017 indicates that the erosion rate may vary considerably but most of the soil gradients originating in rocks will be produced during times of higher erosion rates.

Both conditions (a) and (b) should occur; we have indicated how the dominate condition can be determined from the statistical distribution of track densities in grains with track gradients. In principle we could distinguish between conditions (a) and (b) by appealing to the slopes of the track gradients (Figure 4). In practice these slopes are strongly effected by the shape of the grain, by uneven shielding during irradiation and by loss of material by soil abrasion. Careful mapping of many grains, however, may yield a meaningful average slope. In the above discussion we have assumed that the average level of the solar flare particle flux is the same now as it was when the track gradients were recorded. There is no reason to suppose that this is not true. However long-range variation in flare activity remains a possible, though less likely alternative to variation in erosion rate.

(3) The third broad class of soil grains consists of those which have a uniform track density $\varrho<5 \times 10^{8} \mathrm{~cm}^{-2}$. The lack of a track gradient or very high track density indicates that these grains have never been within a few hundred microns of the surface. Their cosmic ray track record is the result of exposure within the top $\sim 10 \mathrm{~cm}$ of soil (Figure 3) and hence is determined by the history of soil activity.

In the discussion of soil activity which follows we combine the third class of grains with the track densities measured in the center of soil grains having track gradients (the latter being about $20 \%$ of the combined population). These two groups have similar frequency distributions for both cosmic ray and spallation track densities (Comstock et al., 1971) and hence have a similar sub-surface history.

In Figure 6 we have indicated the distribution of cosmic ray track densities in individual soil grains with $\varrho<5 \times 10^{8} \mathrm{~cm}^{-2}$ for several depths in the Apollo 12 double core (Comstock et al., 1971). Arrhenius et al. (1971) have measured similar distributions 


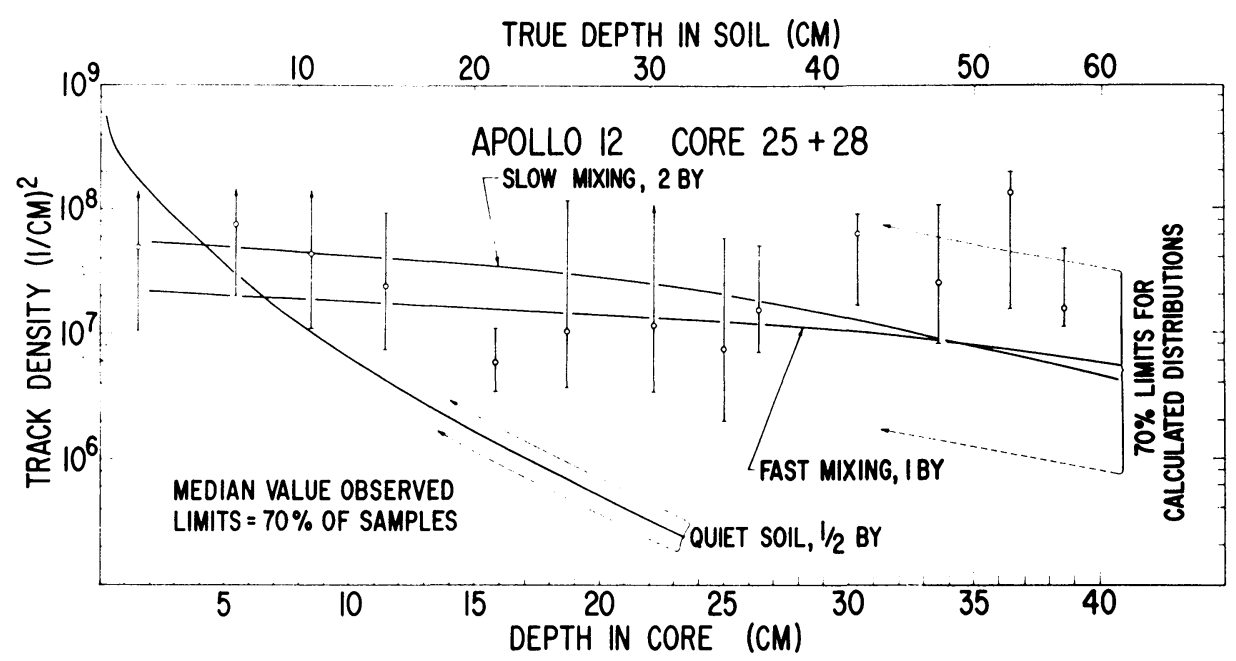

Fig. 6. Cosmic ray track distribution in double core $12025+28$. The data points indicate the observed spread in track density from grain to grain. The curves have been calculated for some models of soil history discussed in the text (see Comstock et al., 1971, for a complete discussion of the data and calculations.) The true soil depths are given by Carrier et al. (1971).

at additional depths. The data points give the median track density observed at each depth and the limit bars show the spread of the $70 \%$ of the samples closest to the median. The statistical error in the measurement of these track densities is typically $\lesssim 10 \%$, so the wide spread in track densities is due to a complex irradiation history for each depth. The 'Quiet soil' curve (Figure 6) is calculated from Equations (2) and (4) for an irradiation time of 500 m.y. Clearly this curve is not consistent with the observations - considerable soil movement has taken place.

As one approximation to this movement we might assume that the soil has suffered continual depth-dependent mixing by meteoroid impact (Shoemaker et al., 1970). We have worked out computer models based on this assumption (Comstock et al., 1971), and the results of two such models are shown in Figure 6 by the curves marked 'slow mixing' and 'fast mixing'. Fast mixing refers to soil mixed to depths $d_{c}$ in time periods $\tau$ (m.y.) $=d_{c}(\mathrm{~cm})$; slow mixing is ten times slower. The mixing time derived by Shoemaker et al. (1970) for soil is $\tau \approx 1.6 d_{c}$ for $d_{c} \sim 10-100 \mathrm{~cm}$. The solid curves in Figure 6 give the calculated median values with the $70 \%$ spread of hypothetical samples and irradiation times as indicated. It is seen that the magnitude and overall distribution of observed track densities is well reproduced by these models.

On the other hand the track density distributions do appear to contain some structure, which is even more evident with the greater statistics given by Arrhenius et al. (1971). In addition the Apollo 12 double core has some well defined visual layers, perhaps as many as 13, through the $60 \mathrm{~cm}$ depth of the sampled soil (LSPET, 1970; Sellers et al., 1971). At least one of these layers correlates strikingly with the structure 
in the track distributions. This is the coarse layer at a true soil depth of $\approx 16-20 \mathrm{~cm}$ which contains a relatively low track density (Arrhenius et al., 1971).

Another model which approximates the movement of the soil has been investigated by Arrhenius et al. (1971). They assume that the soil has been steadily buried by deposited layers, with no mixing between layers and no irradiation prior to deposition. From the track densities in each layer they derive surface residence times for each layer on the order of 0-60 m.y. Arrhenius et al. find that some mixing must still be invoked within each layer in order to explain the distribution of track densities within that particular layer.

Spallation tracks can give us further information on the history of the soil grains. In Figure 7 we have plotted a preliminary distribution of spallation track densities in the Apollo 12 double core. Here again we see a spread, although not as broad as for the cosmic ray tracks. As pointed out by Comstock et al. (1971) the pattern shown here would be expected on the basis of a soil mixing model, but a burial model with no previous irradiation would predict a spallation track density that continued to increase with depth by a factor of $\sim 10$ in the top $60 \mathrm{~cm}$., due to the high spallation production rate (Figure 3.) The spallation tracks in Figure 7 force us to conclude that

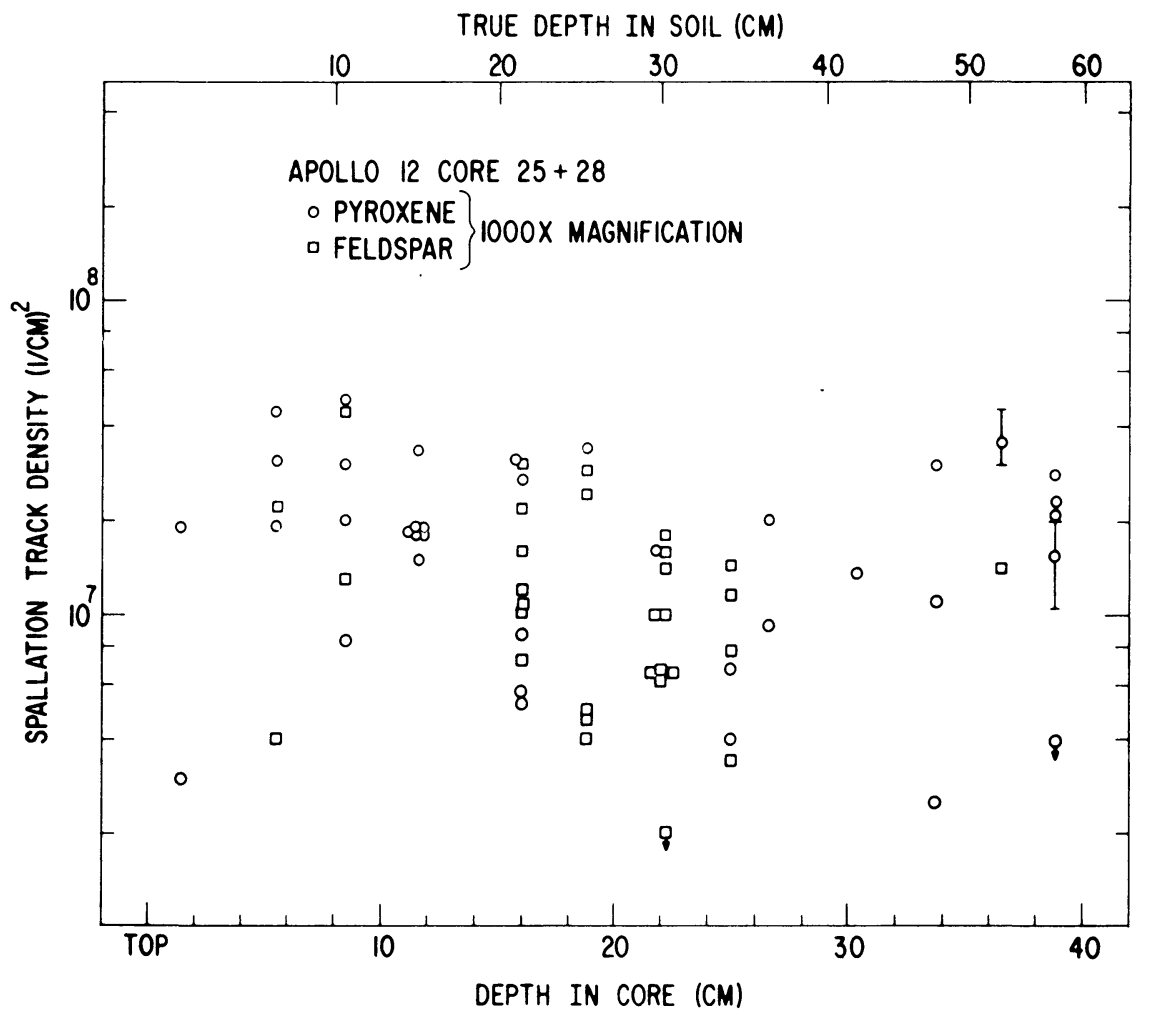

Fig. 7. Preliminary spallation track distribution in double core $12025+28$ (see Comstock et al., 1971 , for acomplete discussion of the data.) 
most of the grains have been pre irradiated in the top $2 \mathrm{~m}$ of soil, or $1 \mathrm{~m}$ of rock, for an integrated time of $\sim 100$ m.y. before excavation, deposition and burial at the core site. This implies a more complex history than simple burial after a single excavation from virgin (trackless) material, for most of the layers.

We know that the Moon is continually bombarded by meteoroids, so that some depth-dependent mixing must be taking place (Öpik, 1969). The nature of these events is such that material is removed from an excavation and deposited in a thin layer around the site. At a given point on the Moon this layering will continue to build up the soil level until an impact occurs near that point, re-excavating some of the deposited material. We know further that there is a correlation between deposition distance from the excavation site and original stratigraphy at the excavation site (Schmitt and Sutton, 1971). The layer deposited at a given point comes from a rather restricted depth interval and thus represents a mixing of only a few of the original layers. Hence each layer may have a distinctly different history. At a given site some layers will have been excavated from deep, previously unirradiated material, while others will be composed of a more mature, better mixed population of soil.

The question which we can ask is: what can we say about the mixing history of each observed layer? Our approach to this question appeals again to the mixing model calculations. These calculations (Comstock et ai., 1971) describe material which has been exposed for some time at various depths in the upper $25 \mathrm{~cm}$ of soil, mixed occasionally with nearly trackless material exposed only at greater depths. As a first approximation this should be similar to the mixing of layers with different exposure histories. Comstock et al. (1971) assumed that the entire double core sample represents one homogeneously mixed population. We now assume that the previous history of

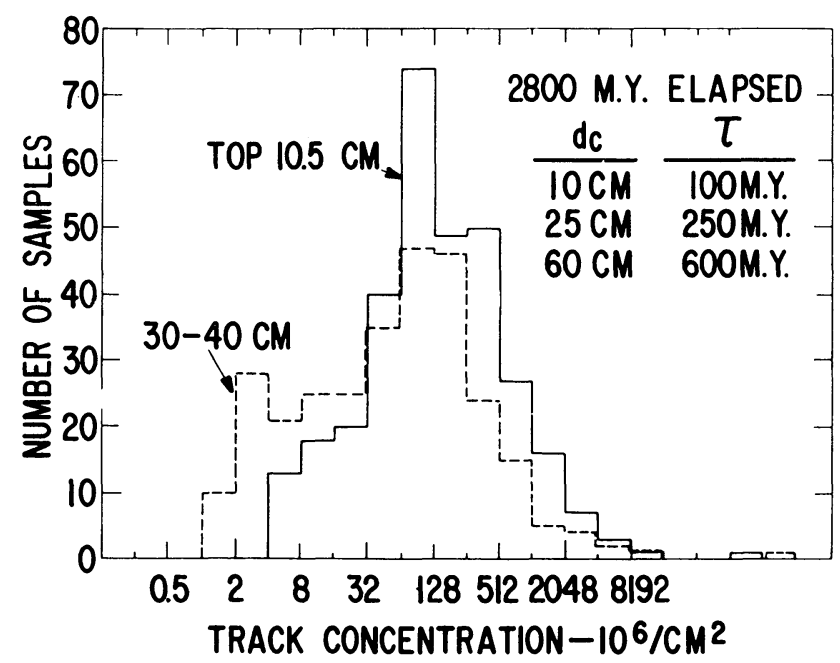

Fig. 8. Calculated distributions of cosmic ray track density after 2.8 b.y. of soil mixing and irradiation. Hypothetical samples were periodically mixed down to three characteristic depths $d c$ with time periods $\tau$. These distributions are characteristic of well-mixed soil. 
a given layer (i.e., before deposition and burial at its present site) is reproduced by a mixing model for some mixing age appropriate to that particular layer.

A layer which is composed of what we shall refer to as 'well mixed' material should have a track density distribution similar to that shown in Figure 8. This distribution is the result of Monte Carlo calculations for hypothetical soil grains subjected to depth-dependent mixing and irradiation for $2800 \mathrm{~m}$.y. It is seen that most of the samples are included in an order-of-magnitude spread around $\varrho \approx 10^{8} \mathrm{~cm}^{-2}$ and many samples occur with $\varrho \gg 10^{8} \mathrm{~cm}^{-2}$. A track density distribution calculated for a soil population which has been mixed for only 1200 m.y. is shown in Figure 9. Here we have



Fig. 9. Calculated distributions of cosmic ray track density after 1.2 b.y. of soil mixing and irradiation. These distributions are characteristic of partially-mixed soil.

a broader distribution with $\varrho \sim 10^{6}-10^{8} \mathrm{~cm}^{-2}$ but still including some samples with $\varrho \gg 10^{8} \mathrm{~cm}^{-2}$. A sample grain population of this kind we shall refer to as 'partially mixed'.

Soil which has been recently excavated from previously undisturbed material will have $\varrho \gg 10^{6} \mathrm{~cm}^{-2}$ (Figure 3). Whatever cosmic ray tracks these grains have were formed after the layer was deposited on the surface. These layers will have predominantly low track densities $\varrho \sim 10^{6}-10^{7} \mathrm{~cm}^{-2}$ with very few, if any samples with $\varrho \gtrsim$ $\gtrsim 10^{8} \mathrm{~cm}^{-2}$. We will refer to such layers as 'unmixed' although it is understood that some very shallow mixing within the layer must take place during its surface residence time.

Using Figures 8 and 9 as prototypes we compare these definitions with the track density distributions found in the various physical layers observed in the Apollo 12 double core (LSPET, 1970). From Figure 6 and the detailed distributions given by Arrhenius et al. (1971) we identify a mixing history with each physical layer in Table IV. The low track density reported for layer VI identifies it as material from an unmixed population (the samples at $\approx 20 \mathrm{~cm}$ in Figure 6 may be associated with this). 
TABLE IV

\begin{tabular}{lcl}
\hline $\begin{array}{l}\text { Layer } \\
\text { designation }\end{array}$ & $\begin{array}{l}\text { Maximum } \\
\text { soil depth }\end{array}$ & $\begin{array}{l}\text { Mixing } \\
\text { history }\end{array}$ \\
\hline X & $1.6 \mathrm{~cm}$ & well mixed \\
IX & 3.1 & partially mixed \\
VIII & 11.8 & well mixed \\
VII & 16.1 & well mixed \\
VI & 19.6 & unmixed \\
V & 24.0 & well mixed \\
IV & 29.7 & partially mixed \\
III-4 & 35.2 & well mixed \\
III-3 & 38.8 & well mixed \\
III-2 & 43.2 & partially mixed \\
III-1 & 52.2 & well mixed \\
II & 58.8 & well mixed \\
I & 76.5 & partially mixed \\
\hline
\end{tabular}

a LSPET (1970); Bhandari et al. (1971)a.

b Carrier et al. (1971); LSPET (1970).

For layers II, III-1, VII, VIII and X the track density distributions given by Arrhenius et al (1971) show sharp peaks in the interval $\varrho \sim 3 \times 10^{7}$ to $10^{8} \mathrm{~cm}^{-2}$ corresponding to the derived distribution for well-mixed soil (Figure 8). The track distributions for layers I and IV are much broader, similar to the distribution in Figure 9 calculated for partially-mixed soil. The other layers, III-2, III-3, III-4, V and IX, appear to be intermediate between Figures 8 and 9.

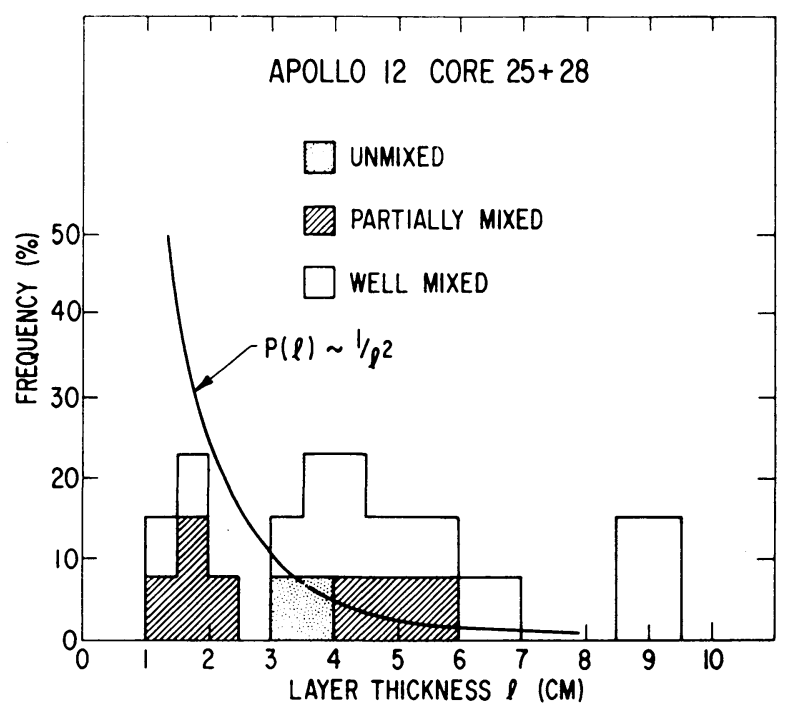

Fig. 10. Frequency distribution of true soil thicknesses of the visual layers in double core $12025+28$. Assigned mixing histories are indicated (Table IV). The curve $P(l)$ represents an expected frequency distribution. 
When compared with physical features (Sellers et al., 1971) we find that those layers identified as well mixed tend to be medium grey, with no internal structure, generally finer-grained with unclear boundaries. This is consistent with a longer history of physical activity (excavation, deposition, abrasion) and a greater homogeneity. The layers identified as partially mixed generally have discernible boundaries and some differences in physical properties. The unmixed layer VI is easily distinguishable from the others and is coarser-grained, consistent with recent excavation from 'virgin' material.

In general, the better-mixed soil has been subjected to more physical activity and more admixture from different localities and depths, tending to be more homogeneous with more of the grains well-irradiated by cosmic rays.



Fig. 11. Hypothetical lunar soil illustrating the formation of Apollo 12 double core layers II and VI according to a model described in the text. Arrangement of the hypothetical parent layers at sites 1 and 3 is not unique. 
The identification of mixing histories allows us to make another inference about the physical layers. In Figure 10 we have plotted the distribution of approximate thicknesses of the visual layers, corrected for compaction (Carrier et al., 1971). In addition we have drawn a curve $P(l) \sim 1 / l^{2}$ representing the expected distribution of thicknesses. This curve was derived by assuming that excavated material is deposited outside the crater in a smoothly thinning blanket (Öpik, 1969) within 1-2 diam of a crater site and taking into account the size frequency distribution of cratering events (Shoemaker et al., 1970). Figure 10 suggests an overabundance of thick layers. However, the thickest layers have been identified as well mixed; hence they may have been built up from several smaller layers of well-mixed material which are not distinguishable because they are too homogeneous.

Our picture of lunar soil, based on the distribution of cosmic ray particle tracks, may be summarized by reference to Figure 11 which shows the hypothetical formation of two of the Apollo 12 double core layers. Figure 11 shows three hypothetical sites, the upper part of site 2 is drawn to represent the Apollo 12 double core $25+28$. The three sites are shown at three different times, site 3 at an early time $T_{1}$, site 1 at a later time $T_{2}$ and site 2 at the present. Each site has been built up by repeated layering (presumably of ejecta blankets). Specifically, we suppose that at time $T_{1}$ an impact occurred at site 3 excavating material down to some depth such as that marked 'Crater A'. Excavated material from some depth interval (marked a in Figure 11) was deposited on the surface at site 2 and become what we know as layer II. Since this material was already fairly well mixed at site 3 it forms a well-mixed layer at site 2 . If the original layers in depth interval $a$ at site 3 had been predominately partially mixed, or included an unmixed layer, then the material deposited at site 2 would have been only partially mixed. Between times $T_{1}$ and $T_{2}$ other layers were deposited at site 2 on top of layer II. Note that the final layering sequence was not necessarily deposited contiguously, that is, several layers may have been deposited on top of layer II, then some of these re-excavated by shallow cratering events and replaced by other layers.

At the later time $T_{2}$ we suppose that an impact event occurred at site 1, excavating material to a great depth (Crater B in Figure 11). Unirradiated soil or subsoil material (depth interval $b$ in Figure 11) was deposited on the surface at site 2, forming the coarse layer VI. Further layering and possibly shallow excavations occurred at site 2 between time $T_{2}$ and the present when the observed layer sequence was sampled.

We have shown that most of the observed layers may come from partially- or wellmixed material, so that most soil grains have experienced several excavations and surface exposures. Each particular surface residence time may therefore be much less than the integrated surface residence time. Since most of the cosmic ray tracks are acquired near the surface, the surface residence times derived by the method of Arrhenius et al. (1971) for the individual layers will be similar to average integrated surface residence times for the soil grains in those layers.

The existence of layers is not inconsistent with mixing by excavation because the stratigraphy below a given depth is not destroyed by excavation of material above that depth. Frequent excavation above a depth $\mathrm{d}$ means that the net burial rate at 
depth $\mathrm{d}$ in general will be less than the average layering rate on the surface. It is expected that spallation tracks in the soil, with their high rate of production in the upper 2 meters, can provide information about this net burial rate, especially for layers with a simple cosmic ray irradiation history (e.g. Apollo 12 double core layer VI).

A relevant physical process which has not been discussed above is the possibility of surface transport (e.g., Gold, 1971). Surface transport over great distances will require that soil grains remain on the surface for relatively long times and can be expected to acquire quite high cosmic ray track densities (the center of a $100-\mu \mathrm{m}$-diam grain on the soil surface will acquire cosmic ray tracks at a rate of $\dot{\varrho} \sim 10^{3} \mathrm{~cm}^{-2}$-yr). Such transport probably can be ruled out for the grains in layer VI (Table IV) which have $\varrho \sim 10^{7} \mathrm{~cm}^{-2}$ (Arrhenius et al., 1971). On the other hand large grains which have very high track densities, $\varrho>10^{9} \mathrm{~cm}^{-2}$ (Barber et al., 1971a, b; Crozaz et al., 1971), represent prolonged exposure and the possibility of surface transport for these grains cannot be eliminated.

\section{Conclusions}

The particle track record of lunar surface history for both rocks and soil can be summarized in three general depth domains (Figure 3).

(1) Direct surface irradiation by solar flare heavy nuclei of the first 0 to $\sim 0.2 \mathrm{~cm}$ results in steep track density gradients which have recorded rock erosion rates of about $10^{-8}$ to $10^{-7} \mathrm{~cm} \mathrm{yr}^{-1}$ (Figure 4). Track gradients in soil grains may indicate a parent rock erosion rate of $\sim 3 \times 10^{-7} \mathrm{~cm} \mathrm{yr}^{-1}$ early in the Moon's history. When the exposure time and erosion rate are known, such as for the glass coating on 12017, then the level of solar particle flux in the past can be determined.

(2) The second depth domain, $\sim 0.2 \mathrm{~cm}$ to $\sim 10 \mathrm{~cm}$, involves irradiation primarily by galactic cosmic ray heavy nuclei. These particle tracks have provided surface residence times for the rocks of $\sim 1$ to $50 \mathrm{~m}$.y. (Table III). Cosmic ray tracks (Figure 6) acquired predominately at these depths record the mixing and layering history of lunar soil. Track distributions in the soil are consistent with a soil history which includes repeated excavation, layering and burial, such that one core $12025+28$ soil layer is unmixed and weakly irradiated whereas the others contain soil which has been better and better mixed while being more and more irradiated (Table IV).

(3) The third depth domain, 0 to $\sim 200 \mathrm{~cm}$, is recorded by the tracks of spallationrecoil nuclei. These tracks indicate that both the rocks and soil grains have a wide range of residence times in the top $2 \mathrm{~m}$ of the lunar surface (Table III, Figure 7).

\section{Acknowledgements}

The author is indebted to R. L. Fleischer and H. R. Hart, Jr. for many helpful comments. This work was supported in part by NASA under contract NAS 9-7898. 
Note added in proof: Recent data on cosmic ray abundances (Cartwright et al., 1971; Binns et al., 1971; Webber et al., 1971) show that Fe is significantly more abundant relative to the $\mathrm{VH}$ group than had been indicated by the earlier data used in Table II, especially at relativistic energies. The improved abundances $A(Z)$ change Equation $1 \mathrm{~b}$ to

$$
\left(\frac{\mathrm{d} N}{\mathrm{~d} T}\right)_{E} \approx 0.6\left(\begin{array}{l}
\mathrm{d} N \\
\mathrm{~d} T
\end{array}\right)_{\mathrm{VH}}
$$

at low energies. Using better (but still uncertain) values of $\Delta R(Z) / \Delta R(\mathrm{Fe})$ for $Z \geqslant 20$ (Plieninger and Kratschmer, 1971) will further change this to

$$
\left(\frac{\mathrm{d} N}{\mathrm{~d} T}\right)_{E} \approx 0.75\left(\begin{array}{l}
\mathrm{d} N \\
\overline{\mathrm{d} T}
\end{array}\right)_{\mathrm{VH}}
$$

which yields values for cosmic ray surface residence times intermediate between the 'high' and 'low' ages given in Table III, for $\Delta R(\mathrm{Fe}) \approx 12 \mu \mathrm{m}$. However there are still uncertainties in $\Delta R(\mathrm{Fe})$ and in the time average of $(\mathrm{d} N / \mathrm{d} T)_{\mathrm{VH}}$ at low energies.

\section{References}

Arrhenius, G., Liang, S., Macdougall, D., Wilkening, L., Bhandari, N., Bhat, S., Lal, D., Rajagopalan, G., Tamhane, A. S., and Venkatavaradan, V. S.: 1971, Proc. Second Lunar Science Conf. 3, 2583 (MIT Press).

Barber, D. J., Cowsik, R., Hutcheon, I. D., Price, P. B., and Rajan, R. S.: 1971a, Proc. Second Lunar Science Conf. 3, 2705 (MIT Press).

Barber, D. J., Hutcheon, I. D., and Price, P. B.: 1971b, Science 171, 372.

Bhandari, N., Bhat, S., Lal, D., Rajagopalan, G., Tamhane, A. S., and Venkatavaradan, V. S.: 1971, Proc. Second Lunar Science Conf. 3, 2599 (MIT Press).

Binns, W. R., Fernandez, J. I., Israel, M. H., Klarmann, J., and Mewaldt, R. A.: 1971, 12th Int. Conf. on Cosmic Rays, Hobart, OG-73.

Borg, J., Maurette, M., Durrieu, L., and Jouret, C.: 1971a, Proc. Second Lunar Science Conf. 3, 2027 (MIT Press).

Borg, J. and Vassent, B.; Durrieu, L., Dran, J. C., and Maurette, M.: 1971, this volume, pp. 298; 309.

Burnett, D., Monnin, M., Seitz, M., Walker, R., and Yuhas, D.: 1971, Proc. Second Lunar Science Conf. 2, 1503 (MIT Press).

Carrier, W. D., III, Johnson, S. W., Werner, R. A., and Schmidt, R.: 1971, Proc. Second Lunar Science Conf. 3, 1959 (MIT Press).

Cartwright, B. G., Garcia-Munoz, M., and Simpson, J. A.: 1971, 12th Int. Conf. on Cosmic Rays, Hobart, OG-63.

Comstock, G. M., Fan, C. Y., and Simpson, J. A.: 1969, Astrophys. J. 155, 609.

Comstock, G. M., Evwaraye, A. O., Fleischer, R. L., and Hart, H. R., Jr.: 1971, Proc. Second Lunar Science Conf. 3, 2569 (MIT Press).

Crozaz, G., Haack, U., Hair, M., Maurette, M., Walker, R., and Woolum, D.: 1970, Geochim. Cosmochim. Acta, Suppl. 1 3, 2051.

Crozaz, G., Walker, R., and Woolum, D.: 1971, Proc. Second Lunar Science Conf. 3, 2543 (MIT Press).

Fleischer, R. L., Price, P. B., Walker, R. M., Maurette, M., and Morgan, G.: 1967, J. Geophys. Res. 72, 355.

Fleischer, R. L., Hart, H. R., Jr., Jacobs, I. S., Price, P. B., Schwarz, W. M., and Woods, R. T.: 1970a, J. Appl. Phys. 41, 958.

Fleischer, R. L., Haines, E. L., Hanneman, R. E., Hart, H. R., Jr., Kasper, J. S., Lifshin, E., Woods, R. T., and Price, P. B.: 1970b, Science 167, 568. 
Fleischer, R. L., Haines, E. L., Hart, H. R., Jr., Woods, R. T., and Comstock, G. M.: 1970c, Geochim. Cosmochim. Acta, Suppl. 1 3, 2103.

Fleischer, R. L. and Hart, H. R., Jr.: 1970d, Proc. Burg Wartenstein Conf. on Calibration of Hominoid Evolution, July 1971, and General Electric Research and Development Center Report, No. 70-C-328.

Fleischer, R. L., Hart, H. R., Jr., Comstock, G. M., and Evwaraye, A. O.: 1971a, Proc. Second Lunar Science Conf. 3, 2559 (MIT Press).

Fleischer, R. L., Hart, H. R., Jr., and Comstock, G. M.: 1971b, Science 171, 1240.

Freier, P. S. and Waddington, C. J.: 1968, Phys. Rev. 175, 1641.

Garcia-Munoz, M. G. and Simpson, J. A.: 1970, '11th Internat. Conf. on Cosmic Rays', Acta Phys. Acad. Sci. Hung. 29, Suppl. 1, 317.

Gold, T.: 1971, this volume, p. 55.

Kohman, T. D. and Bender, M. L.: 1967, in B. S. P. Shen (ed.), High Energy Nuclear Reactions in Astrophysics, Benjamin, Inc., pp. 169-245.

Lal, D., Macdougall, D., Wilkening, L., and Arrhenius, G.: 1970, Geochim. Cosmochim. Acta, Suppl. 1, 3, 2103.

LSPET (Lunar Sample Preliminary Examination Team) 1970, Science 167, 1325.

Öpik, Ernst J.: 1969, in Ann. Rev. Astron. Astrophys. 7, 473 (Annual Reviews, Inc., Palo Alto, Calif.).

Pellas, P., Poupeau, G., Lorin, J. C., Reeves, H., and Audouze, J.: 1969, Nature 223, 272.

Plieninger, T. and Krätschmer, W.: 1971, (Abstract) Trans. Amer. Geophys. Union 52, 268.

Price, P. B., Fleischer, R. L., Peterson, D. D., O'Ceallaigh, C., O'Sullivan, D., and Thompson, A.: 1967, Phys. Rev. 164, 1618.

Price, P. B., Fleischer, R. L., and Moak, C. D.: 1968a, Phys. Rev. 167, 277.

Price, P. B., Peterson, D. D., Fleischer, R. L., O'Ceallaigh, C., O'Sullivan, D., and Thompson, A.: 1968b, Phys. Rev. Letters 21, 630.

Price, P. B., Peterson, D. D., Fleischer, R. L., O'Ceallaigh, C., O’Sullivan, D., and Thompson, A.: 1970a, Hung. Phys. Acta 29, Suppl. 1, 417.

Price, P. B. and O'Sullivan, D.: 1970b, Geochim. Cosmochim. Acta, Suppl. 1 3, 2351.

Price, P. B., Rajan, R. S., and Shirk, E. K.: 1971, Proc. Second Lunar Science Conf. 3, 2621 (MIT Press).

Rajan, R. S. and Price, P. B.: 1971, to be published.

Schmitt, H. H. and Sutton, R. L.: 1971, Presented at Second Lunar Science Conf., Houston, Texas (unpublished).

Sellers, G. A., Woo, C. C., Bird, M. L., and Duke, M. B.: 1971, Proc. Second Lunar Science Conf. 1, 665 (MIT Press).

Shoemaker, E. M., Hait, M. H., Swann, G. A., Schleicher, D. L., Schaber, G. G., Sutton, R. L., Dahlem, D. H., Goddard, E. N., and Waters, A. C.: 1970, Geochim. Cosmochim. Acta, Suppl. I 3, 2399.

Walker, R. M.: 1970, Radiat. Eff. 4, 239.

Wang, J. R.: 1970, Astrophys. J. 160, 261.

Webber, W. R., Damle, S. V., and Kish, J. : 1971, University of New Hampshire, preprint UNH-71-21, and 12th Int. Conf. on Cosmic Rays, Hobart, OG-66. 